\title{
PREFACE
}

This Symposium began with a proposal for a meeting to honour Emeritus Professor Robert Hanbury Brown on the occasion of his 80th birthday. He requested that any such meeting should be on a topic that would be of benefit to the Sydney University Stellar Interferometer (SUSI) program. With SUSI and several other high angular resolution instruments either in operation or coming on line within the next decade, and with advances in astrometry, spectroscopy and in theoretical models of stellar atmospheres and interiors, it appeared to be both appropriate and timely to hold a symposium on "Fundamental Stellar Properties: the Interaction between Observation and Theory."

The emphasis of the meeting was on the critical assessment of the quality, accuracy, and prospects for improvement of the observational data and theoretical models, on the outstanding problems in stellar astrophysics, and on the feasibility of achieving the observational and theoretical advances required for their solution. Invited papers comprised the major part of the oral program and the speakers responded to the challenge issued by the Scientific Organising Committee to critically review the current status and prospects for their area of expertise.

The Symposium was opened by the Chancellor of the University of Sydney, Emeritus Professor Dame Leonie Kramer, who welcomed the 126 participants from 22 countries on behalf of the University. The oral program included 52 invited reviews and papers and 10 contributed papers. In addition, 60 poster papers were displayed for the duration of the meeting and a session was set aside for their viewing.

The social program included a reception, an afternoon cruise on Sydney Harbour and evening visits to the Sydney Observatory-now part of Sydney's Powerhouse Museum - and to a performance of "La clemenza di Tito" at the Sydney Opera House. The Symposium dinner, which was attended by three generations of the Hanbury Brown family, was held at Sydney's Taronga Park Zoo, which has magnificent views across Sydney Harbour to the city centre.

The Editors, on behalf of the Chairs of the Scientific and Local Organising Committees, thank everyone associated with organising the symposium. While the organisation was very much a team effort, we would particularly like to thank the postgraduate students of the Chatterton Astronomy Department for their help both before and during the meeting; Bill Tango for ensuring that the Symposium budget was balanced; and Sioe-Gek Chew for transcribing much of the discussion. Special thanks are due to Johannes 
Andersen, IAU Assistant General Secretary, for his advice and assistance. Finally, we thank all the participants for their contributions to the Symposium, which ensured its success.

T. R. Bedding, A. J. Booth \& J. Davis (Editors)

\section{SCIENTIFIC ORGANISING COMMITTEE}
J. Andersen (Denmark)
J. Davis (Australia; Chair)
Y. Balega (Russia)
R-P. Kudritzki (Germany)
B. Barbuy (Brazil)
D. Lambert (USA)
M. Bessell (Australia)
M. Spite (France)
C. Chiosi (Italy)
D. Vandenberg (Canada)
J. Christensen-Dalsgaard (Denmark)

\section{LOCAL ORGANISING COMMITTEE}

$\begin{array}{lll}\text { T. R. Bedding } & \text { W. A. Lawson } & \text { F. Watson } \\ \text { A. J. Booth (Chair) } & \text { J. W. O'Byrne } & \text { A. E. Vaughan } \\ \text { S-G. Chew } & \text { W. J. Tango (Treasurer) } & \end{array}$

\section{SPONSORS}

The Organising Committees thank the following organisations for their generous financial support which made the Symposium possible:

- the International Astronomical Union

- the Anglo-Australian Observatory

- the Mount Stromlo and Siding Spring Observatories

- the Science Foundation for Physics within the University of Sydney

- the Research Centre for Theoretical Astrophysics, University of Sydney

\section{SPONSORING IAU DIVISION AND COMMISSIONS}

Division IV: Stars

Commission 29: Stellar Spectra

Commission 35: Stellar Constitution

Commission 36: Theory of Stellar Atmospheres 